\title{
Bioorganic and Bioinorganic Chemistry
}

\author{
Edwin C. Constable*, Catherine E. Housecroft*, Marc Creus*, Karl Gademann*, Bernd Giese*, \\ Thomas R. Ward*, Wolf-D. Woggon*, and Antoinette Chougnet*
}

\begin{abstract}
The interdisciplinary projects in bioinorganic and bioorganic chemistry of the Department of Chemistry, University of Basel led to the preparation of new systems that mimic biologically important processes and to the discovery of compounds from natural sources which are very promising with respect to medical applications. The advances in these areas are reported here.
\end{abstract}

Keywords: Avidin · Biomineralization · $\beta$-Carotene $\cdot$ Chloroperoxidase · Cyanobacteria · Cytochrome P450 . Electron transfer · Enzyme models · Heme-thiolate proteins · Iron · Metalloenzymes · Reduction · Ruthenium · Porphyrins $\cdot$ Streptavidin - Titanium dioxide

\section{Biomimetic Splitting of Water}

\section{Edwin C. Constable and Catherine E. Housecroft}
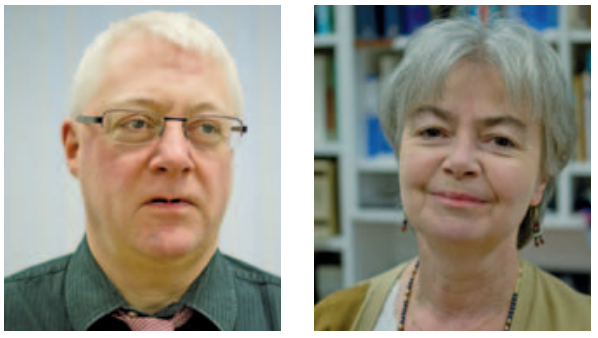

The Constable-Housecroft group is involved in biomimetic and bioinspired chemistry primarily relating to the fundamental processes in nature with a target of designing functional systems of sufficient robustness for practical application. This overview concentrates upon chemical approaches to the splitting of water into $\mathrm{H}_{2}$ and $\mathrm{O}_{2}$ based upon biomimetic or bioinspired principles. Other activities within the group involve the tagging of biomolecules with luminescent metal complexes for intracellular studies (with Prof. Matthias Wymann, Department of Biomedicine) and the deployment of nanoparticles functionalised with laccase for water purification (with Prof. Uwe
Pieles, FHNW). The group has adopted a general strategy of mimicking the biological membrane by using two-dimensional control of the self-assembly of multiple components at solid-liquid or solid-air interfaces.

The ultimate aim for energy production is a coupled water-splitting reaction using solar energy to generate $\mathrm{H}_{2}$ and $\mathrm{O}_{2}$ followed by recombination of the two diatomics in a fuel cell. The formal process is presented in Fig. 1 which serves to highlight the features that need to be controlled. Water oxidation and reduction reactions will take place at spatially separated sites and the kinetics of charge separation will be critical in controlling the success of the devices. The device can be purely molecular or the oxidation and reduction equivalents could be holes and electrons in the valence and conduction bands of a semiconductor or a combination of both approaches.

For the water reduction process the group has taken inspiration from the $\mathrm{Fe}_{2} \mathrm{~S}_{2}$ structural motif found in $\mathrm{Fe}-\mathrm{Fe}$ hydrogenases and invested significant synthetic

Department of Chemistry

St. Johanns-Ring 19

$\mathrm{CH}-4056$ Basel

E-mail: karl.gademann@unibas.ch

*Prof. B. Giese

Department of Chemistry

St. Johanns-Ring 19

$\mathrm{CH}-4056$ Basel

E-mail: bernd.giese@unibas.ch

*Prof. T. R. Ward

Department of Chemistry

University of Basel

Spitalstrasse 51

CH-4056 Basel

E-mail: thomas.ward@unibas.ch

*Prof. W.-D. Woggon, Prof. A. Chougnet

Department of Chemistry

St. Johanns-Ring 19

$\mathrm{CH}-4056$ Basel

E-mail: wolf-d.woggon@unibas.ch,

antoinette.chougnet@unibas.ch

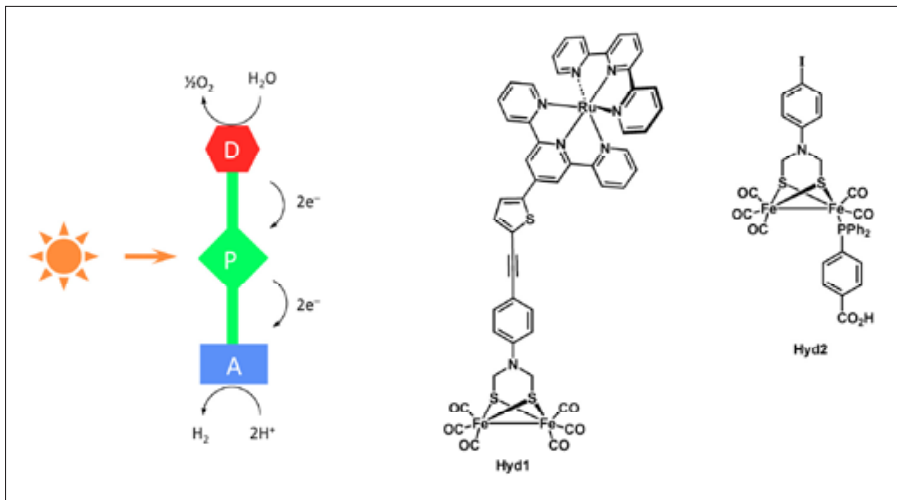

Fig. 1. A general scheme for water splitting using solar-derived photons and two structures developed as biomimetic hydrogenase analogues. 


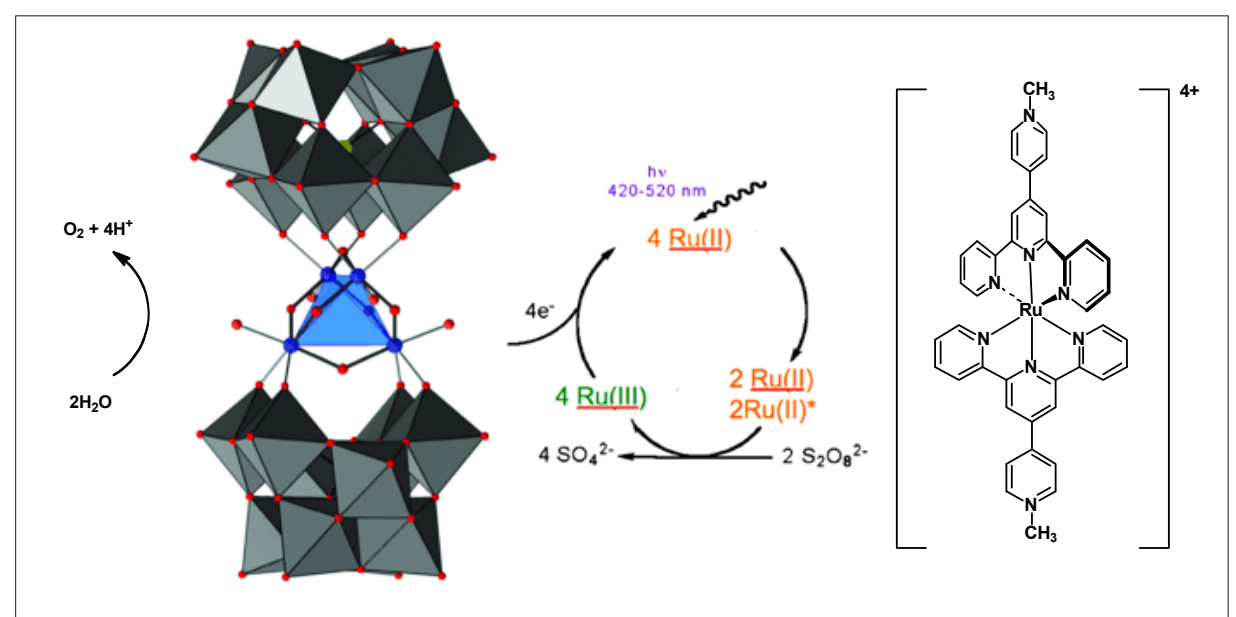

Fig. 2. The general scheme for water oxidation using the Hill cluster and the methyl viologen analogue developed for this work. ${ }^{[5]}$

effort in the preparation of complexes such as Hyd1 (Fig. 1). The Fe $\mathrm{S}_{2}$ cluster is covalently linked to a ruthenium(II) photocentre. Electron transfer from the ruthenium excited state leads to proton reduction and a sacrificial reductant is used to regenerate the ruthenium(II) chromophore. In general these complexes proved to be accessible with the greatest difficulty, and when obtained were very light and water sensitive. ${ }^{[1,2]}$ The next generation system involved the use of $\mathrm{TiO}_{2}$ nanoparticles to support covalently linked photocentres (conveniently available from related work on photovoltaic cells) and $\mathrm{Fe}_{2} \mathrm{~S}_{2}$ clusters functionalised with surface binding groups such as Hyd2. Cells prepared in this manner show a reduced photocurrent and bubbles are visibly observed when the bulk conjugate $\left(\mathrm{TiO}_{2}\right.$, cluster, ruthenium complex) is irradiated in the presence of a sacrificial electrolyte. Current efforts are concentrating upon the quantification of hydrogen production through head-space analysis. In the course of these studies, and in cooperation with Prof. Pieles at the FHNW, a convenient method was developed grafting phosphonate complexes onto $\mathrm{TiO}_{2} \cdot{ }^{[3]}$ The use of the ester for the direct conjugation with the nanoparticles avoids an intermediate step involving hydrolysis of the ester to the free phosphonic acid; this has a significant synthetic advantage because the hydrolysis is surprisingly difficult to achieve quantitatively, with the monoester being the usual product.

Oxygen and hydrogen are the Castor and Pollux twins of water splitting and,

\section{Evolutionary Rules for Metalloenzyme Design}

\section{Marc Creus}

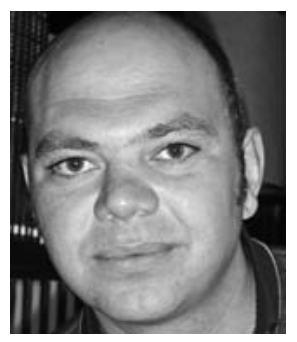

Current work within the newlyestablished Creus group is based on the concept that $d i$ rect metal coordination to non-catalytic proteins may lead to nascent metalloenzymes, which can form a basis for further evolution. Conceptually, the dual ideas of 'emergence' and 'evolution' of metalloenzymes correspond to two extremes of an evolutionary process: i) a qualitative step, involving a new function reached through innovation (e.g. acquisition of catalytic activity from previously inactive form) and ii) a quantitative step (e.g. the improvement of a weak, but detectable function). Directed evolution, despite its limitations in practical terms, ${ }^{[1]}$ provides a powerful tool for the second type (or quantitative) step. ${ }^{[2]}$ Although the study of intermediate steps of improvement of metalloenzymes is likely to contribute greatly to the establishment of engineering ground-rules for designing enzymes de novo, a major challenge remains in the first kind of evolutionary step (i.e. acquisition of function).

Traditionally, the approach adopted for incorporation of a metal within a protein scaffold has depended largely on rational design, much like a synthetic chemist will design metal-ligands or prepare analogues (or derivatives) of a given set of ligands to improve their activity as homogeneous metal-catalysts. ${ }^{[3-5]}$ However, it is widely accepted that the design of proteins de novo to incorporate functional aspects, such as metal binding in a catalytically active form, remains a challenge. The option of rationally remodelling proteins toward a new function only marginally reduces the challenge, despite the distinct advantage that in this case only a fraction of the total design (e.g. the catalytic active site of an enzyme) must be addressed. A recent highprofile example highlights the difficulty of rational enzyme design, in which directed evolution was required to improve the original activity. ${ }^{[6]}$ In simple terms: because design is difficult, evolution is necessary.

To overcome the puzzle of structurefunction relationships in metalloprotein design the Creus group has adopted the general principle that one should work with large libraries and select and evolve those designs with the most attractive characteristics. The basic principles of this approach should also be familiar to medicinal chemists who screen large chemical libraries to 


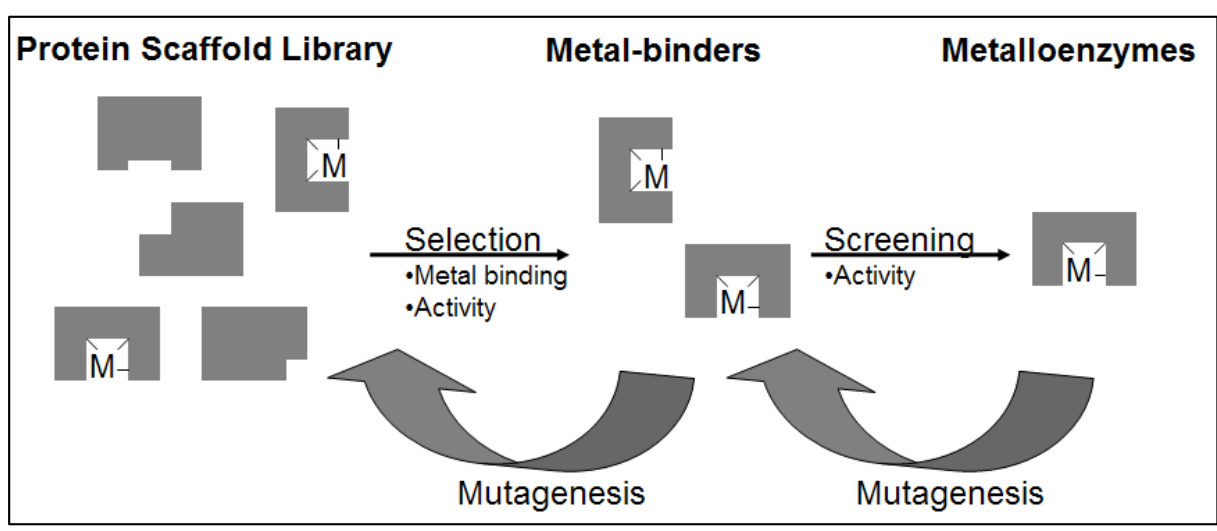

Fig. 1. Simplified overview of selection \& screening of engineered metalloproteins and metalloenzymes. With current tools of molecular biology, an experimental selection can typically be carried out with libraries in excess of tens of millions of protein variants, which allows the testing of a large protein scaffold library. In contrast, screening (an approach familiar to many chemists) is typically limited in practice within the range of tens to thousands of variants or conditions per experiment. Consequently, screening is usually carried out using a subset of variants with a pre-selected activity (e.g. metal-binding). An enriched library, previously selected either experimentally (using molecular biology approaches) or rationally (e.g. in silico) can be further improved and validated by screening. In addition, both selection and screening can be used iteratively following further mutagenesis (back-arrow) in a genetic (evolutionary) algorithm.

find the right inhibitor as well as familiar to inorganic chemists synthesizing large libraries of ligands for homogeneous metalcatalysis. In all these examples, 'hits' are taken for further modification and experimental testing, whereas those initial scaffolds that do not work are quickly abandoned. These are simple, but very powerful forms of Darwinian evolution that are routinely pursued in many labs.

By analogy, it was reasoned that largescale mutagenesis of the protein scaffold and selection for binding of a metal with an appropriate chemistry may provide sufficient diversity of first the coordination sphere (many with subtle variations) such that the 'right' species is found with some detectable catalytic activity. Further screening \& selection of this weak activity may then lead to further improvement of the first and second-coordination spheres, with improved catalytic properties (Fig. 1). Moreover, given detectable catalytic activity, directed evolution may also help to improve other factors, such as substrate binding.

It is evident that the design of the library is crucial to maximise success. On the one hand, small, rational libraries almost certainly miss good 'hits', particularly when we do not have an in-depth understanding of structure-function relationships. In enantioselective catalysis, for example, prediction of structure-function relationships is very difficult. ${ }^{[2]}$ On the other hand, a larger design space offers more hits, although it is limited in practice due to sheer scale and cost.
By applying techniques of molecular biology (e.g. in vivo selection and phage display) and a judicious combination of rational design and evolution, the Creus group has started screening and selecting routinely among hundreds of millions of potential protein variants, a scale currently beyond the reach of most rational design and traditional synthetic chemistry approaches (Fig. 1). These methods for creation of enzymes de novo will provide fundamental insight into the origin and evolution of catalytic activity of metalloproteins in nature. Further, this 'bottomup' approach to bioinorganic chemistry may prove fruitful in addressing questions such as: How can we improve homogeneous metallocatalysts, particularly to work efficiently in aqueous environments, a feat that many enzymes have achieved in nature? Additional practical applications for designed metalloproteins can also be envisaged, such as in sensors, cellular probes, molecular machines and in drugdelivery.

[1] M. T. Reetz, D. Kahakeaw, R. Lohmer, Chembiochem 2008, 9, 1797.

[2] M. Creus, T. R. Ward, Org. Biomol. Chem. 2007, 5, 1835 .

[3] J. Kaplan, W. F. DeGrado, Proc. Nat. Acad. Sci. USA 2004, 101, 11566.

[4] Y. Lu, S. M. Berry, T. D. Pfister, Chem. Rev. 2001, 101, 3047.

[5] I. Bertini, A. Sigel, H. Sigel, 'Handbook on Metalloproteins', Marcel Dekker, New York, Basel, 2001.

[6] O. Khersonsky, D. Rothlisberger, O. Dym, S. Albeck, C. J. Jackson, D. Baker, D. S. Tawfik, J. Mol. Biol. 2010, 396, 1025.

\section{Chemical Biology of Natural Products}

\section{Karl Gademann}

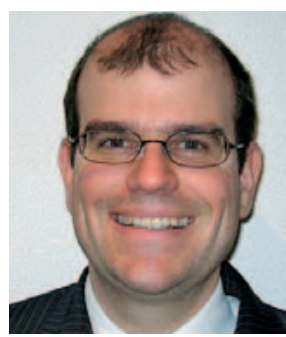

A major line of investigation in the Gademann lab is the isolation and synthesis of natural products in order to understand biological processes at the molecular level. For example, the anguinomycins ${ }^{[1]}$ such as $\mathbf{1}$ were prepared and it was demonstrated that these compounds are inhibitors of nuclear export (Fig. 1). These small molecules are able to disrupt protein/protein interactions between the transport protein CRM1 and its cargo protein. ${ }^{[1 b]}$ In this respect, it is fascinating to see that the truncated analog 2 (red in Fig. 1) almost completely retains the activity of the parent natural product.[1b] Another research effort of the group is directed towards target identification, and it was shown that a target of the cytotoxic lactone goniothalamin (3) is the exportin CRM1.[2]

Scientists in the Gademann lab are also isolating and characterizing new metabolites from natural sources (bioprospecting), and, for example nostocarboline (4) ${ }^{[3]}$ and the aerucyclamides (5), ${ }^{[4]}$ were isolated from the cyanobacteria Nostoc 78-12A and Microcystis aeruginosa PCC7806, respectively. Both compounds are active (the former in vivo $\left.{ }^{[3 \mathrm{c}]}\right)$ against Plasmodium falciparum, the parasite causing malaria.

With support of the European Young Investigator Award Gademann's research is focused to a great extent on natural products that are inducing and enhancing the outgrowth of neurites. These investigations are of relevance in our aging society, as it has been suggested that such compounds might present a therapeutic approach to address neurodegenerative diseases. Farinosone C (6), a neurotrophic metabolite isolated from Paecilomyces farinosus, and derivatives thereof have been synthesized and structure-activity relationships helped to delineate the pharmacophore of this compound. ${ }^{[5]}$ As can be seen in Fig. 1, farinosone $\mathrm{C}$ induces outgrowth of neurites in the PC-12 cellular assay.

In many cases, natural products are powerful modulators of biological activity. To improve their use as tool compounds, spatial and temporal control of bioactivity would be desirable. Accordingly, a new method $^{[6]}$ was developed for surface immobilization of natural products such as vancomycin based on catechol anchors. [7]

These catechols are useful for the chemical modification of many surfaces, ${ }^{[8]}$ 


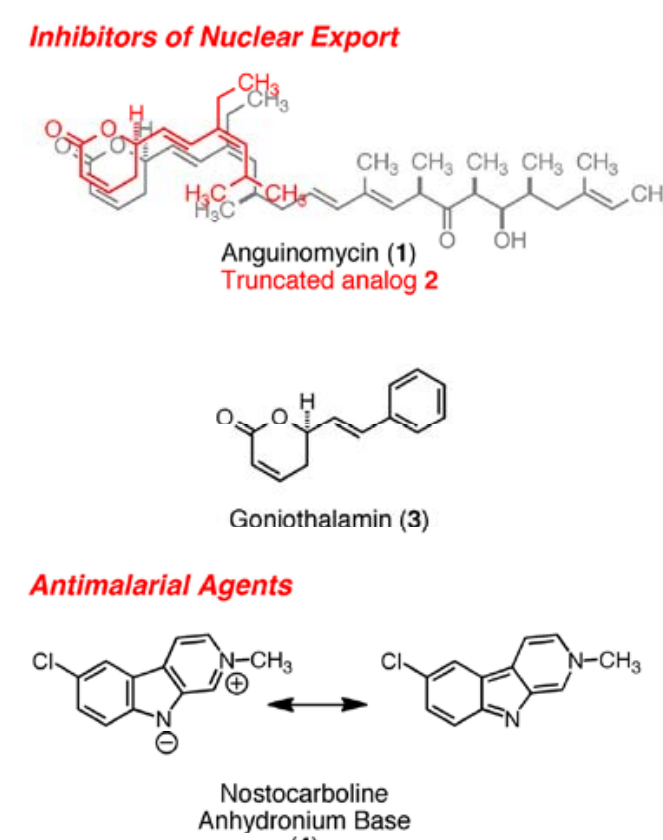

(4)
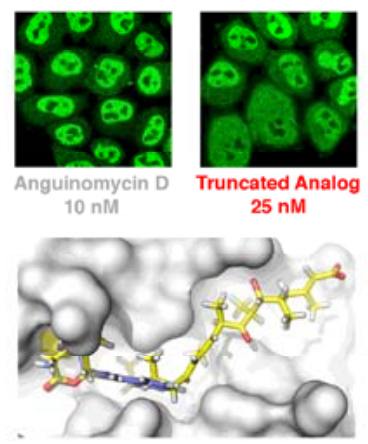

Model of goniothalmin (3) binding to CRM1

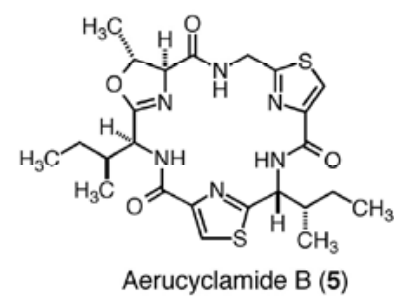

Inducers of Neurite Outgrowth<smiles>CC(/C=C/C(=O)NC(CO)Cc1ccc(O)cc1)=C\C(C)CC(=O)O</smiles>

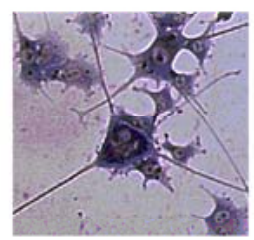

Antimicrobial Surfaces

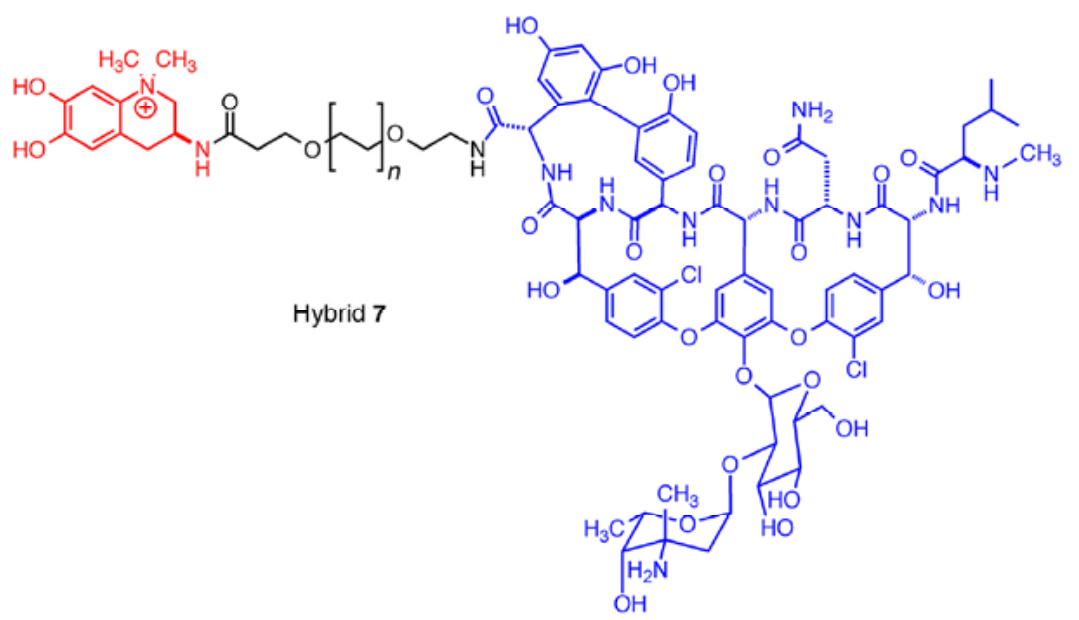

Fig. 1. Natural products interfering with biological systems.

and, for example, the attachment of thin films of poly-ethylene glycol (PEG) allowed for the prevention of aquatic biofouling for over 100 days. ${ }^{[8 a]}$

In addition, it was demonstrated that the immobilization of vancomycin by compounds such as $\mathbf{7}$ led to antimicrobial surfaces that inhibit the growth of Bacillus subtilis. ${ }^{[9]}$ This might be of clinical relevance, as nosocomial infections are rising at an alarming pace and attaching antibiotics directly to biomaterials might constitute an interesting therapeutic approach.
[1] a) S. Bonazzi, S. Güttinger, I. Zemp, U. Kutay, K. Gademann, Angew. Chem. Int. Ed. 2007, 46, 8707; b) S. Bonazzi, O. Eidam, S. Güttinger, J.Y. Wach, I. Zemp, U. Kutay, K. Gademann, $J$. Am. Chem. Soc. 2010, 132, 1432.

[2] J.-Y. Wach, S. Güttinger, U. Kutay K. Gademann, Bioorg. Med. Chem. Lett. 2010, 20, 2843.

[3] a) P G. Becher, J. Beuchat, K. Gademann, F. Jüttner, J. Nat. Prod. 2005, 68, 1793; b) D. Barbaras, M. Kaiser, R. Brun, K. Gademann, Bioorg. Med. Chem. Lett. 2008, 18, 4413; c) S. Bonazzi, D. Barbaras, L. Patiny, R. Scopelliti, P. Schneider, S. T. Cole, M. Kaiser, R. Brun, K. Gademann, Bioorg. Med. Chem. 2010, 18, 1464.

[4] a) C. Portmann, J. F. Blom, K. Gademann, F. Jüttner, J. Nat. Prod. 2008, 71, 1193; b) C.
Portmann, J. F. Blom, F. Jüttner, K. Gademann, J. Nat. Prod. 2008, 71, 1881.

[5] H. J. Jessen, D. Barbaras, M. Hamburger, K. Gademann, Org. Lett. 2009, 11, 3446.

[6] S. Zürcher, D. Wäckerlin, Y. Bethuel, B Malisova, M. Textor, S. Tosatti, K. Gademann, J. Am. Chem. Soc. 2006, 128, 1064

[7] J.-Y. Wach, B. Malisova, S. Bonazzi, S. Tosatti, M. Textor, S. Zürcher, K. Gademann, Chem Eur. J. 2008, 14, 10579.

[8] a) S. Saxer, C. Portmann, S. Tosatti, K. Gademann, S. Zürcher, M. Textor, Macromolecules 2010, 43, 1050; S. Saxer, U. Pieles, M. Elsener, M. Horisberger, S. Tosatti, M. Textor, K. Gademann, S. Zürcher, Prog. Org. Coat. 2010, 67, 20; c) B. Malisova, S Tosatti, M. Textor, K. Gademann, S. Zürcher, Langmuir 2010, 26, 4018.

[9] J.-Y. Wach, S. Bonazzi, K. Gademann, Angew Chem. Int. Ed. 2008, 47, 7123.

\section{Electron Transfer in Biopolymers}

\section{Bernd Giese}

Long-range electron transfer (ET) plays an important role in biological systems. In the 1990s the question was raised: how

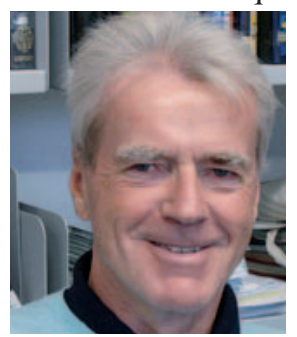
do electrons travel over very long distances (up to $30 \mathrm{~nm}$ in DNA) through biopolymers? According to the Marcus theory ET rates decrease exponentially with distance, thus ET over more than $2 \mathrm{~nm}$ in biopolymers cannot occur by a single-step reaction (superexchange mechanism). The Giese group has solved the problem by showing that ET takes place in a multistep reaction (hopping mechanism). The steppingstones in DNA are the heterocyclic bases. For an oxidative process, where a radical cation migrates through DNA the purines can carry the charge. Guanine $(G)$ is the preferred charge carrier because it is more easily oxidizable than adenine (A), and the charge hops between the Gs in a superexchange mechanism, if the intervening A:T sequence is short (G-hopping). ${ }^{[1]}$ If the A:T sequence is more than $1 \mathrm{~nm}$ long this Ghopping step is so slow that the adjacent $\mathrm{A}$ becomes oxidized and the charge also uses the As as stepping stones (A-hopping). ${ }^{[2,3]}$ For a reductive process the pyrimidines are the stepping stones for the radical anion. Because of similar reduction potentials both thymine (T) and cytosine (C) act as stepping-stones. Excess electrons repair UV-induced DNA lesions, and it was found that one electron acts as a catalyst, cleaving several DNA lesions. ${ }^{[4]}$

After the basic principles of long-range 


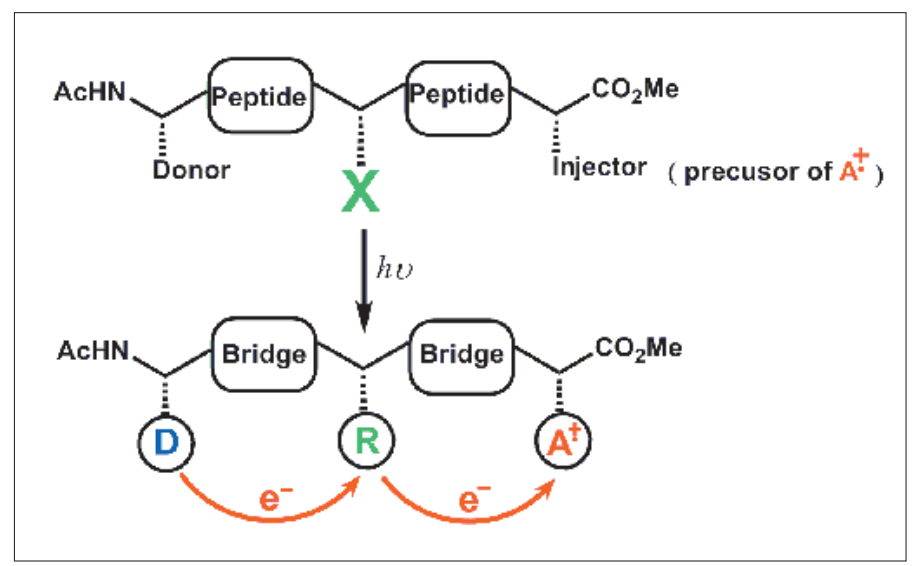

Fig. 1.

ET through DNA were understood, the Giese group posed the question whether a hopping process can also explain longrange ET in proteins (Fig. 1). Nature uses this reaction in energy conversion processes as well as in enzymatic catalysis. In proteins the side-chains of certain amino acids might act as stepping-stones. A peptide assay was developed where the electron acceptor $(\mathrm{A})$ was generated as a radical cation by a laser flash. ${ }^{[5]}$ This electron accepter triggers the electron transfer from the donor (D), and the function of the intermediate amino acid, carrying side chain $\mathrm{X}$ could be measured. Using this assay Giese and his group showed: a) a stepwise process is faster then a one-step reaction, ${ }^{[6]} \mathrm{b}$ ) only certain amino acids can act as stepping stones, which were called relay amino acids, ${ }^{[7]}$ c) ET rates depend upon the direction along the peptide, ${ }^{[8]} \mathrm{d}$ ) charges at the peptides (ammonium and carboxylate groups) influence the ET rate, ${ }^{[9]}$ and e) neighboring groups can influence the efficiency of amino acids as stepping-stones. ${ }^{[8]}$

[1] E. Meggers, M. E. Michel-Beyerle, B. Giese, J. Amer. Chem Soc. 1998, 120, 12950.

[2] B. Giese, J. Amaudrut, A. K. Köhler, M. Spormann, S. Wessely, Nature 2001, 412, 318.

[3] B. Giese, Top. Curr. Chem. 2004, 236, 27.

[4] B. Giese, B. Carl, T. Carl, T. Carell, C. Behrens, U. Hennecke, O. Schiemann, Angew. Chem. Int. Ed. 2004, 43, 1848.

[5] B. Giese, M. Napp, O. Jacques, H. Boudebous, A. M. Taylor, J. Wirz, Angew. Chem. Int. Ed. 2005, 44, 4073 .

[6] M. Cordes, A. Kötgen, C. Jasper, O. Jacques, H. Boudebous, B. Giese, Angew. Chem. Int. Ed. 2008, 47, 3461

[7] M. Wang, J. Gao, P. Müller, B. Giese, Angew. Chem. Int. Ed. 2009, 48, 4232

[8] B. Giese, M. Wang, J. Gao, M. Stoltz, P. Müller, M. Graber, J. Org. Chem. 2009, 74, 3621.

[9] J. Gao, P. Müller, M. Wang, S. Eckhardt, M. Lauz, K. M. Fromm, B. Giese, Angew. Chem. Int. Ed. 2010, 49, in print.

\section{Artificial Metalloenzymes: Enantioselective Catalysis and Beyond}

\section{Thomas R. Ward}

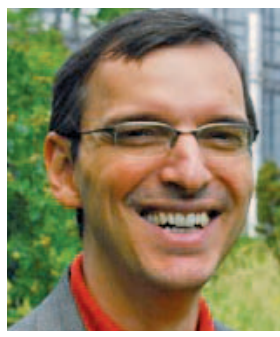

In the past, homogeneous and enzymatic catalysis have grown independently with very little interaction between the respective fields. To many scientists both approaches seemed complementary but not compatible with each other. ${ }^{[1]}$ Thanks to the pioneering efforts of Bäckvall and co-workers on combining hydrolytic enzymes with organometallic catalysts for the dynamic kinetic resolution of alcohols,[2] it appeared that organometallic catalysis may not be incompatible with proteins. Fascinated by the exquisite levels of selectivity and activity achieved by many enzymes,
Thomas Ward speculated that incorporation of a catalytically competent organometallic moiety within a protein scaffold may afford artificial metalloenzymes with properties reminiscent of both homogeneous and enzymatic systems (Fig. 1).[3]

Initial attempts to localize the metal moiety within a protein were based on a covalent attachment. ${ }^{[4]}$ However, it became rapidly clear that a supramolecular anchoring strategy may be more straightforward. Inspired by Whitesides, ${ }^{[5]}$ we turned to the biotin-avidin technology to create hybrid catalysts (Fig. 1).

Thanks to the very high affinity of biotin for either avidin or streptavidin ((strept) avidin hereafter, $\mathrm{K}_{\mathrm{a}}>10^{13} \mathrm{M}^{-1}$ ), this system - commonly coined 'molecular velcro' has found widespread applications in mo-

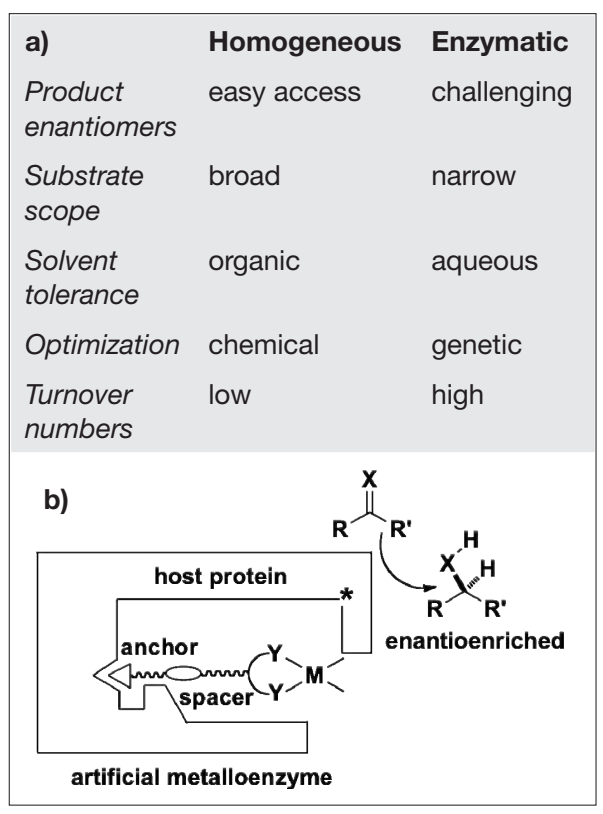

Fig. 1. a) Summary of the pros and cons of homogeneous and enzymatic catalysts; b) artificial metalloenzymes based on anchoring an organometallic moiety within a protein scaffold. Variation of the spacer (oval) and the chelating ligand (chemical optimization) is combined with genetic modification (star) of the host protein (via its gene), thus affording a versatile chemo-genetic optimization strategy.

lecular biology. It was anticipated that appending an organometallic moiety to biotin by means of an amide to the valeric acid side chain of biotin would ensure localization of the catalyst within (strept)avidin, thus providing a well defined second coordination sphere. Circular dichroism (CD) titrations revealed: i) the presence of induced-CD signals, suggesting the presence of a well-defined chiral environment around the metal center and ii) markedly reduced affinities ranging from $\left(10^{6} \mathrm{M}^{-1}<\right.$ $\left.\mathrm{K}_{\mathrm{a}}<10^{9} \mathrm{M}^{-1}\right){ }^{[6]}$ Such affinities, however, ensure that under reaction conditions with [catalyst] $>20 \mu \mathrm{M}$ - nearly all of the catalyst is bound to (strept)avidin, thus alleviating the need for covalent anchoring of the metal moiety to the host protein.

After many unsuccessful attempts using avidin as host protein, a breakthrough occurred upon switching to streptavidin (Sav hereafter). Hydrogenation of $\mathrm{N}$-acetamidoacrylic acid yielded up to $94 \%$ ee in favor of the $(R)$-enantiomer (Scheme 1). [7]

Having established the proof-of-principle, the Ward group focused on various aspects of artificial metalloenzymes. Among these they have: i) implemented robust optimization protocols, ${ }^{[8]}$ ii) strived to improve the turnover numbers and turnover frequencies, ${ }^{[9]}$ iii) applied this approach to other enantioselective transformations, iv) extended the concept to other recognition events and v) exploited other anchoring strategies as well as other host proteins. 

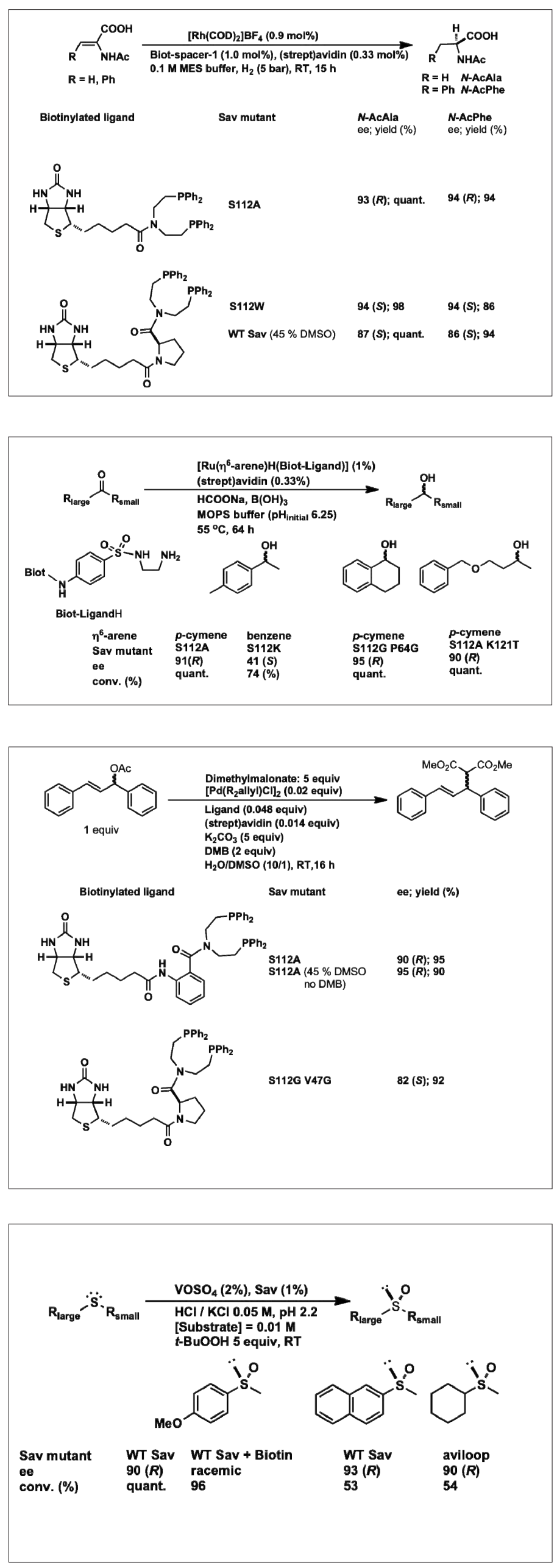

Scheme 1. Artificial hydrogenases for the enantioselective reduction of $\mathrm{N}$-protected dehydroamino acids. Chemo-genetic optimization affords both $(R)$ - and $(S)$ reduction products.

Scheme 2. Selected results for artificial metalloenzymes based on the biotin-avidin technology for the asymmetric transfer hydrogenation of ketones.

Scheme 3. Selected results for artificial alkylases based on the biotin-avidin technology.

Scheme 4. Selected results for artificial sulfoxidases based on the non-covalent incorporation of a vanadyl moiety within streptavidin. See ref. [14a] for the aviloop sequence.
Perhaps one of the most versatile features of artificial metalloenzymes relies on the fact that both chemical and genetic optimization protocols can be exploited to improve the performance of the hybrid catalyst. ${ }^{[10]}$ In most cases, the chemical optimization such as using a conformationally rigid biotin spacer containing enantiopure amino acids ${ }^{[9,11]}$ has a larger impact on the performance of the hybrid catalyst than exchange of an amino acid of the protein. The latter variation can be regarded as a fine tuning step.

This insight led to an expansion of Ward's research ranging from asymmetric transfer hydrogenation of prochiral ketones and imines, catalyzed by $\mathrm{d}^{6}$ piano-stool complexes (Scheme 2); ;12] and palladiumcatalyzed asymmetric allylic alkylation (Scheme 3) ${ }^{[13]}$ towards oxidation reactions including the vanadyl-catalyzed sulfoxidation of prochiral sulfides (Scheme 4) ${ }^{[14]}$ and the dihydroxylation of olefins.

The X-ray structure of $\left[\left(\eta^{6}\right.\right.$-arene $)$ $\mathrm{Ru}$ (biot-en)Cl]CSav revealed two interesting aspects: i) the metal complex is located in the biotin-binding vestibule and ii) the metal complex is surrounded by positively charged surface areas (Fig. 2b). Hence, it seemed intriguing to explore the recognition of this exposed positively charged surface with negatively charged proteins or nucleotides, and investigate possible interactions of the embedded metal complex with such macromolecular targets. To probe this interaction for example with glutathione and various forms of DNA, isothermal titration calorimetry and electrophoretic mobility shift assays were performed using as a control the biotinylated piano-stool complexes $\left[\left(\eta^{6}\right.\right.$-arene $) \mathrm{Ru}$ (bioten)Cl] derived from the well-known 'Sadler-type' complexes. [15]

First results of Ward's group are very encouraging: i) the ternary complex $\left[\left(\eta^{6}-\right.\right.$ arene) $\mathrm{Ru}($ biot-en)Cl]CSav.DNA is much more stable than either Sav.DNA or $\left[\left(\eta^{6}-\right.\right.$ arene) $\mathrm{Ru}($ biot-en)Cl].DNA; ii) tel-DNA is recognized preferentially over ds-DNA; iii) chemogenetic optimization can be used to modulate the affinity of $\left[\left(\eta^{6}\right.\right.$-arene $)$ $\mathrm{Ru}$ (biot-en)Cl]CSav towards its target; charged amino acid residues in the vicinity of the metal play a critical role in determining the affinity towards negatively charged DNA;[16] iv) neither streptavidin nor the biotinylated complex display high affinities towards ds-DNA or telomericDNA (tel-DNA); v) The presence of competing targets such as gluthatione does not prevent the binding towards tel-DNA: $\left[\left(\eta^{6}-\right.\right.$ arene)Ru(biot-en)Cl]CSav-tel-DNA.

Another offspring of Ward's research concerning streptavidin-biotin conjugates relates to mimetics of collagen that are fiber proteins supporting the biomineralization of hydroxyapatite for bone calcifica- 


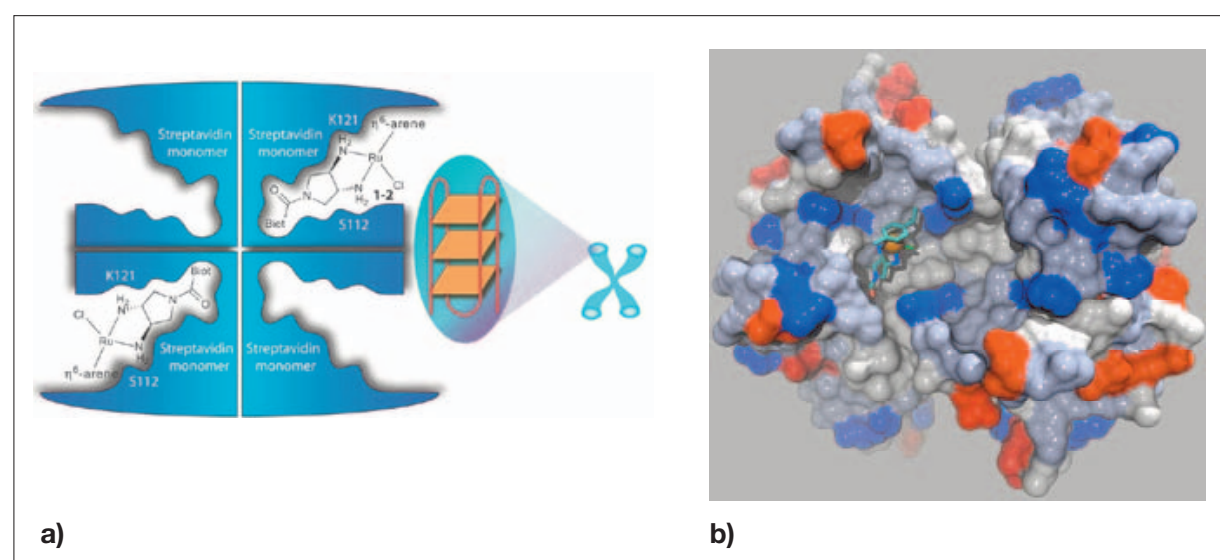

Fig. 2. a) The protein display strategy applied to $\left[\left(\eta^{6}\right.\right.$-arene $) \mathrm{Ru}($ biot-en) $\mathrm{Cl}] \subset \mathrm{Sav}$ for the selective recognition of tel-DNA and b) close-up view of the X-ray structure of $\left[\left(\eta^{6}\right.\right.$-cymene)Ru(biot-en) $\mathrm{Cl}] \subset$ Sav revealing a positively charged shallow surface (blue) around the metal favoring extensive interactions with target DNA.

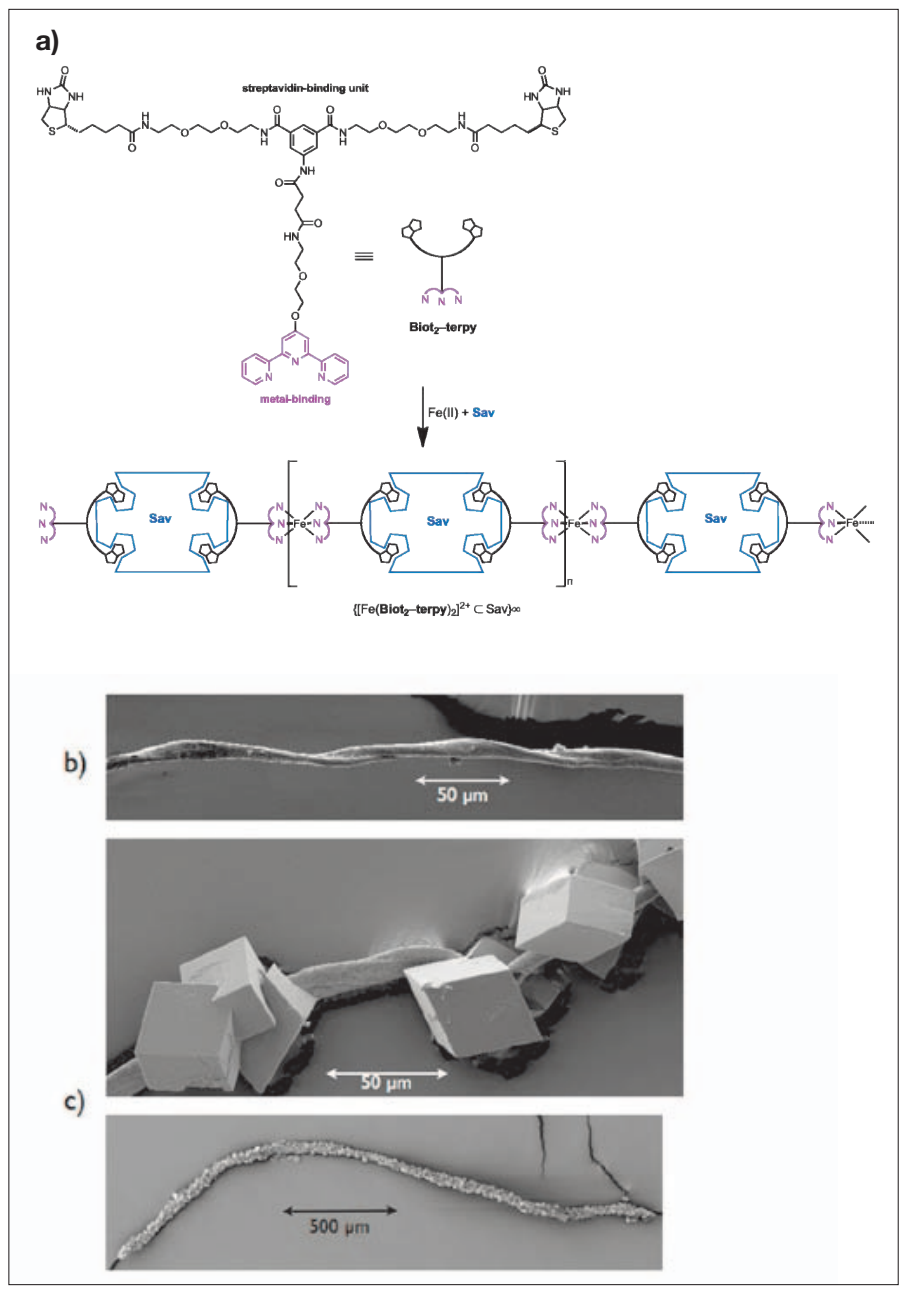

Fig. 3. a) Protein Organo-Metallic Frameworks based on the biotin-avidin technology; b) in the presence of calcium, the Sav polymer forms bundles as revealed by SEM; c) adding $\mathrm{Ca}^{2+}$ and $\mathrm{CO}_{2}$ leads to the biomineralization of calcite on the Sav bundles.

tion. To construct a collagen mimic, welldefined protein aggregates are required, and it was speculated such polymers could be constructed using the homotetrameric nature of Sav. Accordingly, a bis-biotinylated anchor was prepared to ensure that both biotin anchors bind to a single Sav tetramer in a cis-fashion. ${ }^{[17]}$

Two such bis-biotin anchors can be linked thanks to the presence of a terpyridine moiety which binds cooperatively to form $\left[\mathrm{Fe}(\text { terpyridine })_{2}\right]^{2+}$, thus creat- one-dimensional polymer. Since streptavidin carries 48 carboxylate residues on its surface, the addition of $\mathrm{Ca}^{2+}$ leads to the formation of protein bundles (Fig. 3b) as revealed by electron microscopy. Upon addition of both $\mathrm{Ca}^{2+}$ and $\mathrm{CO}_{2}$, these fibers template the biomineralization of calcite (Fig. 3). ${ }^{[18]}$

\section{Acknowledgements}

The research projects of Thomas Ward are supported by the Swiss National Science Foundation (Grants FN 200020-113348 and 200020-126366), the Canton of Basel as well as the Marie Curie Training Networks IBAAC and BIOTRAINS (FP6-MRTN-CT-2003-505020 and FP7-ITN-238531). His group enjoys cooperations with Prof. Tilman Schirmer (Biozentrum) for the structural characterization of hybrid catalysts, Prof. Markus Meuwly for the in silico design of artificial metalloenzymes, Prof. Wolfgang Meier towards in vivo catalysis as well as Prof. Daniel Gygax and Prof. Uwe Pieles (FHNW) for the characterization of the POMFs.

[1] T. R. Ward, Chem. Eur. J. 2005, 11, 3798.

[2] O. Pàmies, J.-E. Bäckvall, Chem. Rev. 2003, $103,3247$.

[3] A. Pordea, T. R. Ward, Chem. Commun. 2008, 4239.

[4] S. Duclos, T. R. Ward, H. Stoeckli-Evans, Helv. Chim. Act. 2001, 84, 3148.

[5] M. E. Wilson, G. M. Whitesides, J. Am. Chem. Soc. 1978, 100, 306.

[6] a) A. Loosli, U. E. Rusbandi, J. Gradinaru, K. Bernauer, C. W. Schläpfer, M. Meyer, S. Mazurek, M. Novic, T. R. Ward, Inorg. Chem. 2006, 45, 660; b) M. Skander, N. Humbert, J. Collot, J. Gradinaru, G. Klein, A. Loosli, J. Sauser, A. Zocchi, F. Gilardoni, T. R. Ward, $J$. Am. Chem. Soc. 2004, 126, 14411.

[7] J. Collot, J. Gradinaru, N. Humbert, M. Skander, A. Zocchi, T. R. Ward, J. Am. Chem. Soc. 2003, 125, 9030.

[8] M. Creus, T. R. Ward, Org. Biomol. Chem. 2007, 5, 1835.

[9] U. E. Rusbandi, C. Lo, M. Skander, A. Ivanova, M. Creus, N. Humbert, T. R. Ward, Adv. Synth. Catal. 2007, 349, 1923.

[10] G. Klein, N. Humbert, J. Gradinaru, A. Ivanova, F. Gilardoni, U. E. Rusbandi, T. R. Ward, Angew. Chem. Int. Ed. 2005, 44, 7764.

[11] M. Skander, C. Malan, A. Ivanova, T. R. Ward, Chem. Commun. 2005, 4815.

[12] a) M. Creus, A. Pordea, T. Rossel, A. Sardo, C. Letondor, A. Ivanova, I. LeTrong, R. E. Stenkamp, T. R. Ward, Angew. Chem. Int. Ed. 2008, 47, 1400; b)A. Pordea, M. Creus, C. Letondor, A. Ivanova, T. R. Ward, Inorg. Chim. Acta 2010, 363, 601.

[13] J. Pierron, C. Malan, M. Creus, J. Gradinaru, I. Hafner, A. Ivanova, A. Sardo, T. R. Ward, Angew. Chem. Int. Ed. 2008, 47, 701.

[14] a) A. Pordea, M. Creus, J. Panek, C. Duboc, M. Novic, D. Mathis, T. R. Ward, J. Am. Chem. Soc. 2008, 130, 8085; b)A. Pordea, D. Mathis, T. R. Ward, J. Organomet. Chem. 2009, 694, 930.

[15] Y. K. Yan, M. Melchart, A. Habtemariam, P. J. Sadler, Chem. Commun. 2005, 4764.

[16] M. J. Zimbron, A. Sardo, T. Heinisch, T. Wohlschlager, J. Gradinaru, C. Massa, T. Schirmer, M. Creus, T. R. Ward, Chem. Eur. J. 2010, 16, 12883.

[17] K. J. Hamblett, B. B. Kegley, D. K. Hamlin, M. K. Chyan, D. E. Hyre, O. W. Press, D. S. Wilbur, P. S. Stayton, Bioconjugate Chem. 2002, 13, 588 .

[18] S. Burazerovic, J. Gradinaru, J. Pierron, T. R. Ward, Angew. Chem. Int. Ed. 2007, 46, 5510. 


\title{
Enzymes and Enzyme Mimics
}

\author{
Wolf-D. Woggon and Antoinette Chougnet
}

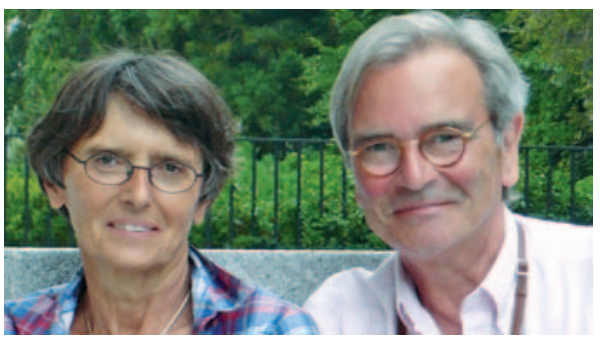

Research of the Woggon group is focused on new enzymes, enzymatic reaction mechanisms and the synthesis of inhibitors and catalytically competent enzyme models. In this context the group has discovered two enzymes related to the biosynthesis of vitamins (Scheme 1): i) a non-heme iron protein $(60.3 \mathrm{kD})$ catalyzing the central cleavage of $\beta$-carotene 1 to retinal $2^{[1,2]}$ and the enzyme tocopherol cyclase $(41.3 \mathrm{kD})$ which cyclizes phytylhydroquinones such as $\mathbf{3}$ to $\gamma$-tocopherol $\mathbf{4}$, one of the members of vitamin E compounds. ${ }^{[3]}$

The reaction mechanisms of these enzymatic transformations were elucidated revealing that the reaction $\mathbf{1} \rightarrow \mathbf{2}$ is in agreement with a monooxygenase formalism ${ }^{[4]}$ whereas the ring closure of $\mathbf{3} \rightarrow \mathbf{4}$ proceeds by $s i$ protonation of the double bond and concomitant $r e$ attack of the phenol. ${ }^{[3]}$ Corresponding enzyme mimics were prepared, for example the bis- $\beta$-cyclodextrin-Ru porphyrin $\mathbf{5}$ contains a perfect supramolecular binding site for hydrophobic carotenoids ( $\mathrm{K}$ $=8 \times 10^{6} \mathrm{M}^{-1}$ ) and ruthenium porphyrin that in the presence of tert-butyl hydroperoxide (TBHP) becomes reactive to cleave the central E-configured double bond of carotenoids (Scheme 2). ${ }^{[5]}$ The design of enzyme mimic 6 takes into account that the enzyme tocopherol cyclase binds the substrate in a particular conformation in order to allow for the enantioface-selective protonation of the phytyl double bond by a weakly acidic amino acid. From compound $\mathbf{6} \alpha$-tocopherol can be obtained with $78 \%$ de. ${ }^{[6]}$

Another long-lasting project of the Woggon group relates to the significance of heme-thiolate proteins such as cytochrome P450 and chloroperoxidase (CPO). ${ }^{[7]}$ Several enzyme models were synthesized (711, Fig. 1.) to understand the importance of the unusual thiolate ligand with respect to chemical reactivity, redox potential of the system and spin state changes during the catalytic cycle.

From these investigations catalytically competent complexes such as $\mathbf{9}$ emerged and recently the complete catalytic cycle of cytochromes P450 including several intermediates could be observed by stoppedflow techniques. ${ }^{[8]}$

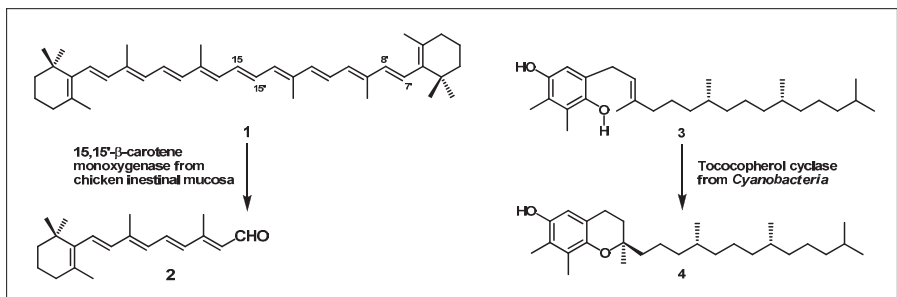

Scheme 1. Enzymes significant to vitamin $A$ and vitamin $E$ formation.

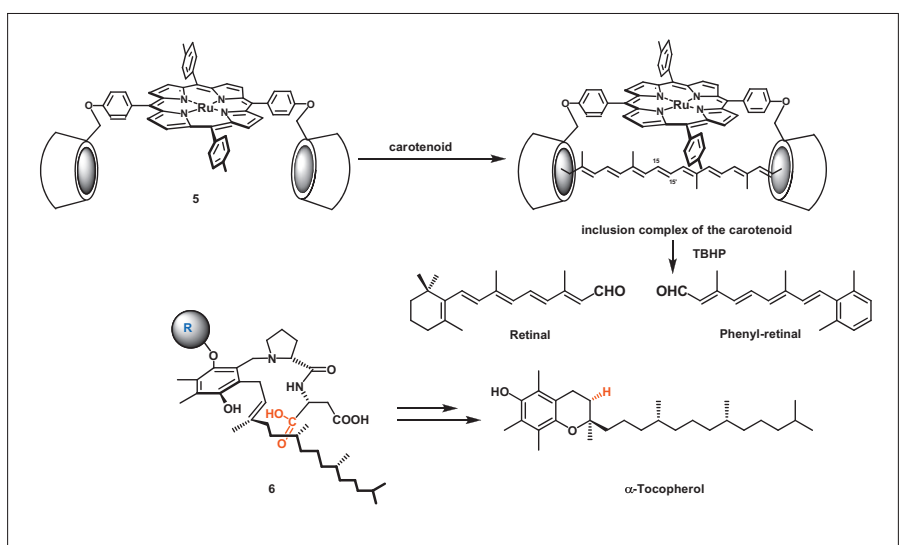

Scheme 2.

Enzyme models of 15,15 '- $\beta$-carotenemonooxygenase, and tocopherol cyclase.

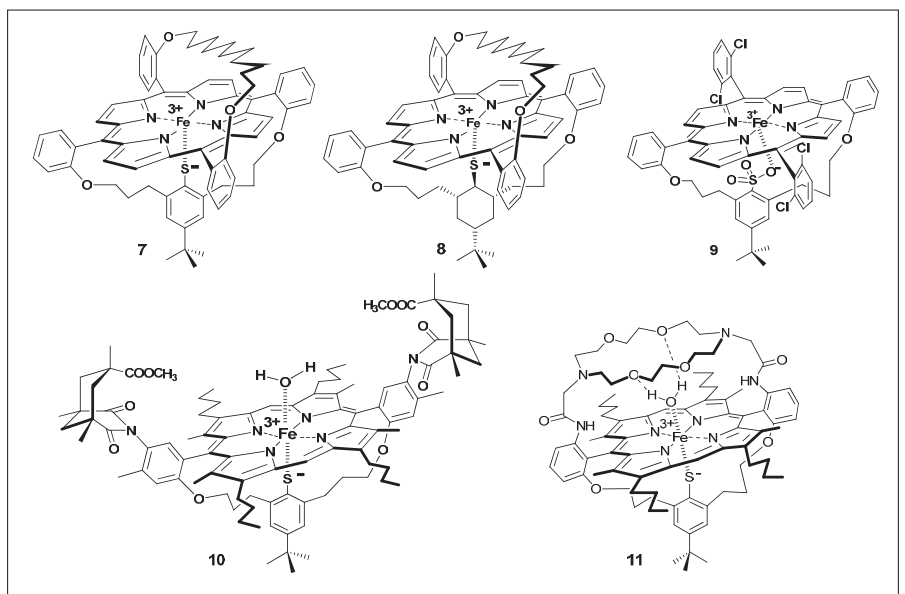

Fig. 1. Synthetic enzyme models of cofactors of hemethiolate proteins.
It is interesting to note that $\mathbf{7}$ is the first P450 model compound that displays the exceptional reactivity towards non-activated $\mathrm{C}-\mathrm{H}$ bonds, i.e. one of the $\mathrm{CH}_{2}$ groups of the alkane bridge is hydroxylated by the $\mathrm{Fe}(\mathrm{IV})=\mathrm{O}$ complex generated by reacting 7 with $\mathrm{PhIO}$. However, the redox potentials of 7 and the corresponding cyclohexyl thiolate complex $\mathbf{8}$ are rather negative $\left(\mathrm{E}_{\mathrm{o}}\right.$ $>-600 \mathrm{mV}$ ) as compared to the ES complex of the enzyme $\mathrm{P} 450_{\text {cam }}\left(\mathrm{E}_{\mathrm{o}}=-170 \mathrm{mV}\right)$ This situation changes when the thiolate is replaced by a sulfonate group, the $\mathrm{E}_{\mathrm{o}}$-value of 9 is $-175 \mathrm{mV}$, moreover 9 is a rather robust catalyst for P450-like oxidations. The complexes $\mathbf{1 0}$ and $\mathbf{1 1}$ have been prepared to understand why the resting state of cytochrome P450 cam $\left(-\mathrm{S}^{-\cdots \cdot \mathrm{Fe}}\right.$ (III) *.. $\mathrm{OH}_{2}$-cluster) is a low-spin system. EPR measurements revealed that $\mathbf{1 0}$ is a highspin complex whereas for $\mathbf{1 1}$, that offers $\mathrm{H}$-bonding to the water molecule bound to
$\mathrm{Fe}(\mathrm{III})$, a low-spin compound was detected. It was concluded that the low-spin character of $\mathrm{P} 450$ is due to polarization of the distal water cluster rendering the water directly coordinating to iron $\mathrm{HO}^{-}$-like. ${ }^{[7]}$

Chloroperoxidase (CPO) is a very versatile heme-thiolate protein that inter alia halogenates substrates. The mechanism of halogenation was poorly understood until the Woggon group prepared enzyme models such as $\mathbf{1 2}$ (Fig. 2), and spectroscopically identified adducts $\mathbf{1 3}$ and $\mathbf{1 4}$ of which the latter is a catalytically competent reagent halogenating activated $\mathrm{C}-\mathrm{H}$ bonds. ${ }^{[7]}$ Due to this information corresponding intermediates of the enzymatic reaction could be identified using CPO from Caldariomyces fumago.

In all organisms cytochrome $\mathrm{P} 450$ isozymes play an important role in the metabolism of exogenous and endogenous compounds, notably in human organs such as 

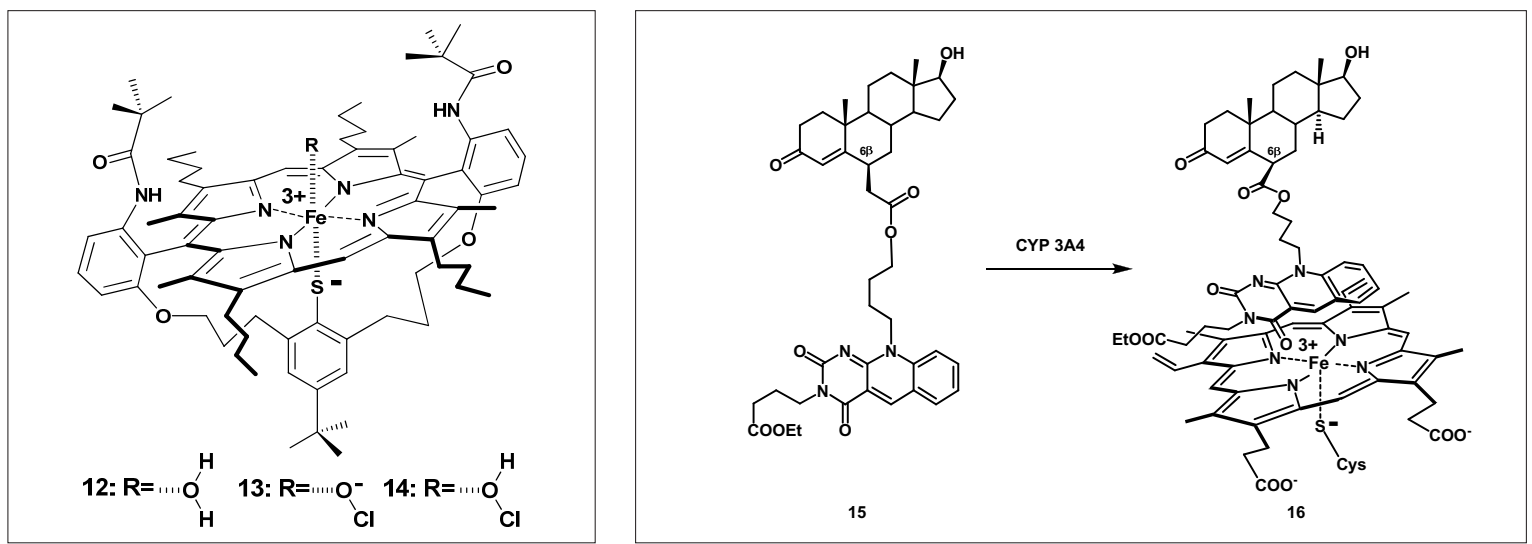

Fig. 2. Enzyme mimics of chlorperoxidase (CPO).

liver and lungs. Of particular interest is the fact that $c a .50 \%$ of drugs are metabolized by CYP 3A4, one of the P450 enzymes in human liver accounting for a large number of documented drug-drug interactions associated with CYP 3A4 inhibition. The aim of Woggon's research in this area was the development of compounds blocking the different binding sites of CYP 3A4 such that the affinity of drug candidates could be evaluated by displacement of a single probe without performing tedious enzyme inhibition studies. Favourably these compounds display a $\mathrm{IC}_{50}$ between 1-10 $\mu \mathrm{M}$ which is considered to be a cutoff value to eliminate drugs binding too strongly to CYP 3A4. These features were accomplished using the synthetic steroid derivative $\mathbf{1 5}$ of which the fluorescence of the deazaflavin chromophore is quenched on binding to the heme-thiolate cofactor of
CYP 3 A4 (see 16, Scheme 3). ${ }^{[9]} \mathrm{IC}_{50}$ values of $\mathbf{1 5}$ are in the desired range between $1-4 \mu \mathrm{M}$. Hence this method can be used to rapidly screen a series of drug candidates identifying compounds whose high affinity to CYP 3A4 may lead to dangerous drug-drug interactions when administered together with other CYP 3A4 substrates.

\section{Acknowledgements}

Financial support of these research projects by the Swiss National Science Foundation, F. Hoffmann-La Roche AG and DSM is gratefully acknowledged.

[1] A. Wyss, G. Wirtz, W.-D. Woggon, R. Brugger, M. Wyss, A. Friedlein, H. Bachmann, Biochem. Biophys. Res. Commun. 2000, 27, 334

[2] A. Wyss, G. Wirtz, W.-D. Woggon, R. Brugger, M. Wyss, A. Friedlein, G. Riss, H. Bachmann, W. Hunziker, Biochem. J. 2001, 354, 521.

[3] A. Chougnet, K. Liu, W.-D. Woggon, Chimia 2010, 64, 303; and references cited therein.
[4] M. G. Leuenberger, C. Engeloch-Jarret, W.-D. Woggon, Angew. Chem. Int. Ed. 2001, 40, 2614.

[5] W.-D. Woggon, Curr. Org. Chem. 2010, 14, 1362; R. R. French, P. Holzer, M. G. Leuenberger, W.-D. Woggon, Angew. Chem. Int. Ed. 2000, 39, 1267.

[6] C. Grütter, E. Alonso, A. Chougnet, W.-D. Woggon, Angew. Chem. Int. Ed. 2006, 45, 1126.

[7] W.-D. Woggon, Acc. Chem. Res. 2005, 38, 127; W.-D. Woggon in Metal Ions in Life Sciences 2007, 3 ('Ubiquitous Roles of Cytochrome P450 Proteins'), 27.

[8] N. Hessenauer-Ilicheva, A. Franke, D. Meyer, W.-D. Woggon, R. van Eldik, Chem. Eur. J. 2009, 15, 2941; N. Hessenauer-Ilicheva, A. Franke, D. Meyer, W.-D. Woggon, R. van Eldik, Rudi. J. Am. Chem. Soc. 2007, 129, 12473.

[9] A. Chougnet, Y. Grinkova, D. Ricard, S. Sligar, W.-D. Woggon, ChemMedChem 2007, 2, 717; A. Chougnet, C. Stoessel, W.-D. Woggon, Bioorg. Med. Chem. Letters 2003, 13, 3643.

Received: October 11, 2010 